\title{
SOCIAL AND PSYCHOLOGICAL FACTORS IN NARCOTICS ADDICTION
}

\author{
John A. Clausen*
}

I

\section{INTRODUCTION}

Narcotics addiction is both a psychophysiological state and a social category. It is a product of behavior learned within a social context and cannot be adequately understood apart from that context. The prevalence and consequences of drug addiction in any society depend as much upon the social and legal definitions placed upon the nonmedical use of narcotics as upon the nature and effects of narcotics or the nature of persons who become addicted. These definitions generally evolve in harmony with the general orientations of the society toward various types of experience, though in some instances, they may be imposed by groups having special interests in and concerns about the problem of narcotics use and addiction.

In contemporary North America, narcotics addiction tends to be regarded with horror. The "dope fiend" and the drug peddler are subject in the popular mind to the same loathing and abhorrence that attaches to the "sex maniac." The addict's apparent lack of will power and rejection of goals other than the support of his drug habit are utterly antithetical to the Protestant ethic, with its injunction to moral responsibility and striving.

Intensifying the strong social disapprobation of the addict has been the change in legal definition attaching to drug use and drug possession since passage of the Harrison Act in $1914{ }^{1}$. The maintenance of addiction now requires that one be a criminal, whereas addicted persons could previously obtain their drugs at very low cost through legitimate drug channels. This action was, of course, designed to protect the population against the dangers of addiction through innocent medicinal use or self-experimentation with narcotic drugs. Coupled with the new legal definition of drug use, however, came the designation of the addict as "enemy" by enforcement personnel and the solidifying of underworld ties and identifications on the part of many addicts. Thus, stereotypes of the addict were reshaped and widely circulated and, to a degree, they were confirmed by the subsequent responses of addicts forced to work out new modes of survival. It is beyond the scope of this paper to explore the

* A.B. 1936, A.M. 1939, Cornell University; Ph.D. 1949, University of Chicago. Chief, Laboratory of Socio-environmental Studies, National Institute of Mental Health, U. S. Department of Health, Education, and Welfare. Author, Sociology and the Field of Mental Health (i956), The Impact of Mental IIINESS ON THE FAMILY (1955), and several research monographs. Contributor to sociological and psychiatric periodicals.

${ }^{2}$ Act of Dec. I7, I914, c. I, 38 STAT. 785 , as amended, 26 U. S. C. $\$ \$ 470$ I-36 (Supp. III, 1956). 
larger social process whereby cultural orientations to narcotics addiction are shaped, but it is important to note that such orientations are not immutable.

It must be noted also that there are a number of societies in which the nonmedical use of narcotics is tolerated or even accepted. Among the Chinese literati, opiumsmoking was long an approved way of achieving a highly valued contemplative state. Hsu notes the appropriateness of this practice in terms of a general tendency of 2

... the situation-centered Chinese . . . to seek harmony with the environment . . . in drugs like opium which enable a person to retreat into a state where conflict with the environment is reduced even more and the likelihood of giving vent to an individual whim is even more remote.

Carstairs has also noted how general cultural orientations influence specific attitudes toward intoxicants, contrasting the Brahmin's use of hashish with the Rajput's use of alcohol. ${ }^{3}$ These groups live side by side in India. The Rajput, a warrior group, live in anxiety that they may not prove adequate in the face of danger. They are readily inclined to escape from their anxieties in the convivial relaxation of the drinking party. The Brahmin, on the other hand, are governed by a code of asceticism which completely rules out the use of alcohol. But by drinking bhang, a concoction of hashish, they achieve a more profound mystical experience, which is the goal they seek.

To cite yet another example of the way in which social meanings determine the consequences of drug use, Slotkin has recently listed some of the uses of peyote (a cactus button whose chief narcotic ingredient is mescaline) among American Indian tribes prior to 189 I. $^{4}$ These include individual use to reduce fatigue and hunger, to treat medical conditions, to induce visions for supernatural revelation, and as an intoxicant, and collective use in tribal rites and as a basis for a religious cult.

From these examples, and many others which might be drawn from the anthropological literature, it seems clear that narcotics use may serve a variety of functions both for the individual and for the collectivity to which he belongs. Group membership, rather than individual personality make-up, is frequently the determinant of drug use. In some instances, such use seems to entail addiction; in others, ritual elements may be paramount, and infrequency of use coupled with injunctions against nonritual use may tend to prevent addiction for most participants.

Turning again to the United States, we may ask whether there are collectivities within which narcotics use is tolerated or even approved. If so, it is important to understand the basis for membership in such collectivities and the social supports of a practice so vigorously condemned in the larger society. As a first step toward exploring these matters, we shall review currently available data on the distribution and social background of narcotics addicts in the United States.

\footnotetext{
${ }^{2}$ Francis L. K. Hsu, American and Chinese 62 (I952).

${ }^{3}$ Carstairs, Cultural Factors in the Choice of an Intoxicant, 15 Q. ST. Anc. 220 (1954).

‘ Slotkin, Peyotism, x 521-189I, 57 AM. ANTkRopologist 202 (I955).
} 


\section{The Distribution of Drug Adpiction in the United States}

The total number of drug addicts and their distribution in the population can only be estimated from the number and characteristics of those who become known to the courts and to treatment centers. Unfortunately, few court systems or hospitals have systematically tabulated data on the characteristics of addicts who have been apprehended or have come for treatment. As a consequence, our over-all knowledge is based on fragmentary data from a number of sources, perhaps the best of which is constituted by statistics on addicts treated at the Public Health Service hospitals. A much greater measure of information is provided by the findings of recent extensive studies of addiction in New York and Chicago.

The nature of available data on drug addicts precludes any analysis of rates of addiction for regions or states. The Public Health Service hospitals at Lexington, Kentucky, and Fort Worth, Texas, receive addicts from all states, both as federal prisoners and as voluntary patients. In recent years, roughly one-half of these addicts have come from four populous states with large metropolitan areas-New York, Illinois, Texas, and Ohio. ${ }^{5}$ These states, together with the District of Columbia, not only send more patients to the Public Health Service hospitals for treatment of addiction than do any other states, but are represented by a higher rate of patients relative to the total population. Moreover, the great bulk of this group of hospital admissions is comprised of voluntary patients who have come from metropolitan areas in the states mentioned. Strictly comparable data for an earlier period are not available, though Pescor's analysis of the first group of admissions to the Lexington hospital suggests less concentration in metropolitan areas two decades ago. ${ }^{\circ}$

It appears also that there has been a significant increase in recent years in the proportion of Negro drug addicts and in the proportion of adolescents and young adults who are addicted. Less than ten per cent of the addicts received at the Lexington Public Health Service Hospital during its first year were Negroes; in recent years, nearly two-thirds have been Negroes. Less than ten per cent of the addicts received two decades ago were under twenty-five years of age; in recent years, over thirty per cent have been under twenty-five years of age.

The same trends are clearly evident in data from a number of communities. In Chicago, for example, Dai analyzed the characteristics of 2,439 addicts who were arrested on narcotics charges or treated for addiction during the period 1928-34. ${ }^{7}$ Eight per cent were under twenty-five years of age. Seventy-seven per cent were white (overwhelmingly native-born), seventeen per cent were Negro, and six per cent were members of other racial groups, largely Chinese. At that time, these other

\footnotetext{
${ }^{5}$ These and other data on recent admissions to the Public Health Service hospitals for the treatment of narcotics addiction are derived from unpublished tables prepared in the Division of Hospitals, United States Public Health Service.

- See Michael J. Pescor, A Statrstical Analysis of the Crinical Records of Hospitalized Drug ADDICTS (U. S. P. H. REP. Supp. No. 143, 1943).

${ }^{3}$ Binghas Dar, Opium Addiction in Chicago (1937).
} 
racial groups comprised less than one per cent of the Chicago population, Negroes comprised seven per cent, and whites ninety-two per cent. In a study made two decades later, the staff of the Chicago Area Project found that nearly one-half of the approximately 5000 drug users officially known to the Police Narcotics Bureau and other agencies was under twenty-five years of age. ${ }^{8}$ Negro narcotics users now constitute a substantial majority of those users known to official sources in Chicago.

Pescor's study of early admissions to the hospital at Lexington revealed an educational distribution not markedly different from that of the total population at the time, except for the unduly high proportion of graduates of professional schools. The latter finding reflects the relatively high rate of addiction among physicians, nurses, pharmacists, and dentists, all of whom have ready access to narcotics. The greatest concentration occupationally was in the domestic and personal service category, especially among waiters, porters, and the like. ${ }^{9}$ All major occupational groups were well represented, however. Dai's Chicago study revealed a generally similar occupational distribution of addicts: disproportionately high numbers in the personal service trades and in entertainment, but, nevertheless, a broad representation of major occupational categories. ${ }^{10}$ Dai's sample did not include physicians and druggists, because of restrictions on the use of records relating to offenses of this group. Tabulations of recent admissions to the Public Health Service hospitals indicate little change in the occupational categories which are overrepresented in the addict population. As a consequence of the younger age of the addicts recently admitted, however, more are reported as having no regular occupation. It must be noted that the occupational designation of many addicts does not represent a continuing or current mode of earning a living, since many engage in illegal pursuits. Nevertheless, in examining the process whereby narcotics use is learned, we shall note that certain occupational groups are much more strategically placed for such learning than are others.

Perhaps the most revealing picture of the distribution of narcotics use in metropolitan populations is afforded by mapping the residences of drug users and computing the rates of known users per thousand of population. Dai carried out such an analysis in the earlier study referred to above. Nine of Chicago's rzo subcommunities, as then delineated, contained roughly five per cent of the total population, but fully half of the known narcotics users.11 The areas with high rates of drug addicts were areas of lowest socioeconomic status and of greatest urban blight. They were characterized by low proportions of persons living in family groups, high population mobility, high rates of juvenile delinquents and adult criminals, and, indeed, high rates of a wide variety of social problems. Family groups living in such areas tended to be migrants of relatively recent years, sifted into the least desirable

\footnotetext{
${ }^{8}$ Illinots Institute for Juvenile Research, Drug Addiction Among Young Persons in Chicago

PEscon, op. cit. supra note 6 , at 27.

${ }^{10}$ Dar, op. cit. supra note 7 , at 53.

11 See $i d$. at 78 .
} (1953). 
areas of residence, largely because they were least advantaged in the competitive process.

The more recent researches of the staff of the Chicago Area Project reveal that the residential distribution of the great bulk of present drug users is very similar to that found by Dai two decades ago. In the intervening period, however, there has been a considerable change in the population of many of the areas of highest drug use. The expanding Negro population has replaced earlier foreign-born migrants who had settled in some of these deteriorated areas of the city. The personal characteristics of residents of many of these areas have, thus, changed, but the problematic social characteristics of the areas are essentially the same.

A similar residential concentration of drug users was found by Chein and his associates in studies of the distribution of narcotics use among adolescents in New York City. ${ }^{12}$ Three-fourths of the adolescent users were found to live in just fifteen per cent of the city's census tracts. These tracts constituted the poorest, most crowded, and most physically dilapidated areas of the city. Further, within these tracts, drug use was highest where income and education were lowest and where there was the greatest breakdown of normal family living arrangements. They were, in large part-but by no means exclusively-areas of residence of the Negro and Puerto Rican population of the city. On the other hand, many other areas of Negro and Puerto Rican residence which were less deprived and less socially disorganized had low rates of drug use.

In no subcommunities of New York or Chicago does it appear that a majority of the population is addicted to the use of narcotics. There are areas in both cities, however, where as many as ten per cent of the young adult males have been apprehended or treated for narcotics possession or addiction. We must look, then, to the conditions of life within these areas for clues as to the factors which make narcotics addition so much more prevalent there than in the larger society.

\section{III}

\section{InduCtIon to NARCOTICS USE}

The most essential precondition to becoming a narcotics addict is, of course, that one have access to narcotics and to a knowledge of how they are used. Beyond this, one must have some motivation for trying the drug-whether to relieve pain, to produce euphoria, to please a loved person, to achieve acceptance in a group, or to achieve some other goal. The goal need have little to do with the specific effects of the narcotic. Moreover, the motivation or goal of initial drug use must be sharply distinguished from the motivation to maintain a drug habit. The latter is a product of learning which seems to depend on the interaction between drug effects,

${ }^{12}$ Chein, Studies in Narcotics Use Among luveniles, I Socral Work 50 (1955). The problem of the juvenile user is explored in greater detail elsewhere in this symposium. Chein and Rosenfeld, Juvenile Narcotics Use, infra 52-68. 
especially in the first experience of withdrawal, and the self-conception of the drug user.

Prior to the passage of the Harrison Act, many persons became habituated to narcotics through the use of patent medicines containing opium derivatives. Some of these persons apparently remained unaware of their dependency upon narcotics and so can hardly be termed addicts. That many became addicted, however, is evidenced by the number of popular "cures" that were offered for chronic opium intoxication. ${ }^{13}$ These ranged from home remedies which simply substituted one narcotic form for another to private hospitals or sanatoria, with profit rather than therapy the primary aim in most instances.

Subsequent to I9I4, the environment of most Americans did not provide easy access to narcotics for nonmedical use. How, then, have additional addicts been created? Have they been recruited systematically by drug peddlers? Have they been grossly deviant persons who sought out illegal sources of supply in order to experience drug euphoria?

For information on the process of induction to drug use, we must rely upon the addict's own story. Often this story is slanted so as to put the subject in a favorable light. Nevertheless, there is sufficient corroboration in the stories of many persons with divergent backgrounds and attitudes to say that, by and large, addiction is not primarily to be ascribed to the effectiveness of drug peddlers or to initial purposive seeking after narcotics on the part of those who become users.

The studies of Alfred Lindesmith and Bingham Dai in the 1930's suggest that the most usual pattern of induction into drug use was through intimate personal association with an addict. In many instances, this person was not sought out because he was an addict; this fact was discovered after a personal tie had been established. Dai notes that: ${ }^{14}$

The process in which this pattern of opium addiction is taken over by an individual is not very much different from that in which other cultural patterns are transmitted. In a number of cases we found that the drug habit was started less for the effect of the drug than as a sign of identification with the group they happened to be in.... This process of identification is found to take place when a young person associates with an older one who uses drugs and who, because of the habit or otherwise, commands the former's admiration and respect, or when two persons are in some form of love relationship ... when one of them is a drug user.

Such identifications most often took place in settings where the individuals were removed from effective ties with conventional groups to which they had belonged. Some of Dai's subjects were introduced to drugs at "pleasure parties," to which they were taken by more experienced friends or dates. Others were introduced to drugs by prostitutes or in homosexual relationships, through pool-hall and dance-hall associations, through association with co-workers in hotels and restaurants, or, in a

${ }^{13}$ See Charres E. Terry and Mildred Pellens, The Opium Problem esp. c. 2 (1928).

${ }^{14} \mathrm{DAI}$, op. cit. stupra note 7 , at $\mathrm{I} 73$. 
few instances, by the purposive urging of peddlers. Most of these addicts had not started life in the areas where drug use is most prevalent. They had come to such areas for a variety of reasons-in search of inexpensive living quarters, in the course of employment (bellhops, porters, entertainers), or in search of freedom from the restraints of the moral order of the larger society. Many were deviants from conventional morality well before they had tried drugs.

The recent increase in addiction by younger persons suggests some change in the mode of induction to drug use. Undoubtedly, some adult users are still becoming addicts through associations in settings removed from their home communities. Many of the younger users, on the other hand, are acquiring drug habits in their home communities. Psychiatric and sociological studies of younger addicts are in agreement in finding that most of these boys acquired their first experience with drugs in a group setting or at the initiative of a close friend. ${ }^{15}$ Sometimes several friends would decide, in the course of collective activities, to try marijuana or heroin for "kicks." In other instances, an experienced boy would introduce others to drugs at or preceding parties. Most young drug users first smoke marijuana and then go through a progression of steps in heroin use-from snuffing to subcutaneous injection to intravenous injection. There is general agreement that the great majority of these users were not tricked into addiction by drug peddlers. There seems also to be general agreement that the narcotics use of these recent addicts is to be understood, at least in part, in terms of social processes and problems of adjustment which are widespread in the slum areas where drug addiction is most prevalent.

The individual who becomes a narcotics user often passes through a number of stages in becoming incorporated into groups where delinquency and drug use are habitual behavior patterns. Becker has analyzed the stages in becoming a marijuana user in terms of the person's relationships to the controls of the larger society. ${ }^{\mathbf{1 6}}$ Typically, the prospective marijuana user is introduced to the drug through participation in some group, one or more of whose members has access to a source of supply. The drug is most often proffered by an experienced user who teaches how it can be used to produce the desired effect.

The neophyte is likely to worry about the consequences of being found out. He is reassured by the more experienced boys who appear to engage in the activity with impunity. The beginner may share the popular stereotype of the marijuana user as one whose will power is destroyed and whose behavior rapidly becomes uncontrollable. If such moral reservations or the fear of consequences are strong enough, they prevent the exposed subject from succumbing to the temptation of trying the drug. Often, however, the novice will acquire observations and rationalizations which permit him to reject the stereotype, to try a "reefer," and to justify occasional use.

${ }^{15}$ In addition to Chein's reports, supra note 12, see Fort, Heroin Addiction Among Young Men, I7 Psychintrx 25I (1954); Zimmering et al., Drug Addiction in Relation to Problems of Adolescence, 109 Am. J. Psychitry 272 (1952).

${ }^{10}$ Becker, Marihuana Use and Social Control, 3 Social Problems 35 (1955). 
Occasional use is, at first, a function of availability-which entails being with others who can provide the marijuana-but in time, there is likely to be a move toward finding a stable source of supply. With continued use, efforts to conceal the fact from nonusers are likely to persist, but one achieves greater feeling of safety in the presence of other marijuana users. There is now also a clearer rejection of the conventional moral injunctions against drug use, coupled with such rationalizations as the observation that conventional persons may engage in much more harmful activities-for example, use of alcohol.

Finally, Becker observes, the occasional user may become a regular user, with his "connections" for securing a supply of the drug, a fairly well-established mode for avoiding the problem of detection and for coping with pressures from conventional persons relative to drug use, and a rationale for handling the issue of morality in the face of his emotional dependence on the drug.

Many marijuana users do not become opiate users. Indeed, it appears that marijuana use is much more widely prevalent both in northern metropolitan areas and in the Southwest than is the use of opiates. Owing, however, to the apparent coalescence of sources of marijuana and of heroin supply in recent years, and owing to the fact that marijuana use may constitute a major step toward identification with unconventional values and activities, Becker's analysis is a substantial contribution to our knowledge of the process of becoming a heroin user.

In most instances, it appears that the sequence which includes first marijuana use and then heroin use is itself a late phase of a much longer process whereby the individual is incorporated into a subculture whose norms are deviant from those of the larger society. The social settings within which the process occurs may vary somewhat, as may the specific subcultural contexts which are learned. The most common form of setting within which deviant or unconventional behaviors are learned is that of "street-corner society."17 Many adolescents and young adults in urban slum areas interact with their peers "on the street" during most of their waking hours. Such interaction is much less under the surveillance of adult or authority figures and much less subject to conventional controls than is the social activity of adolescents and young adults in more favored communities.

\section{IV}

\section{Aspects of Life in the Urban Stum}

We have noted that the areas of highest rates of drug use tend to be areas of residence of the most disadvantaged groups or individuals and of other persons whose residence there reflects rootlessness or a desire to participate in unconventional behavior without undue restriction. In most such areas, there is high mobility, a continuous sifting of population. The great diversity of origins of population, the pressing concern with immediate problems of subsistence and gratification, the power

\footnotetext{
${ }^{17}$ The term was coined by William F. Whyte, who studied social relationships among young adults in an urban slum in a northeastern city. See William F. Whyte, Street Corner Society (I943).
} 
wielded by representatives of the organized underworld-these and many other aspects of the social order in such areas effectively prevent concerted action for community social controls on the part of those local residents who desire a more stable and moral order.

The picture of the delinquent subculture found within the urban slum has been drawn many times. Perhaps less familiar is the fact that the law-abiding and morally responsible citizens of such areas also tend to share many beliefs and attitudes which are different from those held in the larger middle-class society. Middle-class Americans often find it difficult to realize that the goals to which they aspire and the values which they take for granted do not entirely pervade the population. Socioeconomic status is significant not merely in terms of the physical style of life that can be maintained and the security from want that is offered by a stable and adequate income; it is also reflected in the approach one takes to pleasure and to pain. The lower-class pattern of life, for example, puts a high premium on immediate physical gratification, on free expression of aggression, on spending and sharing. Cleanliness, respect for property, sexual control, educational achievement-all highly valued by middle-class Americans-are of lesser importance to the lower-class family or are phrased differently.

The merits of conventional morality are easily perceived by the child growing up in a middle-class family. To a considerable degree, his wants will be taken care of and his future assured if only he will follow the precepts that are presented to him by his family, the schools, and the many character-building associations with which he comes into contact. The child growing up amid the disorganization of an urban slum, however, has available neither the models upon which to pattern himself nor the assurance that being "good" will pay off. Indeed, he is likely to hear and see that "everybody has his racket" and to learn early in life that this applies to the representatives of law and order as well as to underworld groups. Attitudes toward authority and identifications with other persons are, of course, significant dimensions in personality development, helping to determine one's responses to social situations and to determine success and failure in many undertakings.

Students of personality development in the urban slum have pointed up a number of sources of personality distortion or vulnerability which frequently characterize child-rearing in this social milieu. ${ }^{18}$ These include absence of a stable father figure in the family, exposure to the overtly exploitative use of sex, repeated frustrations of affectional needs, rebuffs related to minority-group status, and a host of more subtle influences. The consequences are seen in frequent manifestations of personal insecurity, problems of sexual identification on the part of males, rebellious attitudes toward authority, and various defensive maneuvers and tendencies to escape through gambling, intoxicants, and other "kicks."

\footnotetext{
${ }^{18}$ See, e.g., Abram Kardiner and Lioned Ovesey, The Mark of Oppression: A Psycho-social Study of the American Negro (195i); James S. Plant, Personality and the Cultural Pattern (1937); B. M. Spinley, The Deprived and the Privileged: Personality Development in English SocteTY (I953).
} 
Returning more specifically to narcotics use in street-corner society, we may note that it is one form of the search for "kicks" which frequently dominates the activities of groups of youths who find conventional activities and opportunities unattractive. The availability of narcotics within such areas is, of course, related to the fact that adult drug users and drug suppliers can best live and operate in these areas. Dai found that three-fifths of his sample of Chicago addicts lived within the same census tract as that in which they were apprehended for selling or possessing drugs. ${ }^{19}$ The opportunities of adolescent and adult residents of these areas to come into contact with users and suppliers are, thus, numerous. Moreover, in such areas, Chein found that even among junior high school students, a substantial proportion had tolerant attitudes toward drug use, coupled with almost complete ignorance about drug effects and the consequences of addiction.

The research findings and interpretations thus far examined have borne upon the sociological question: Why is drug use most prevalent in certain areas and among certain population groups? We turn next to the more strictly psychological aspect of the problem: Why do some persons become drug users and addicts while others from the same environments resist doing so?

\section{V}

\section{Personality and Drug Adpiction}

Research on the role of personality variables in narcotics addiction has been carried out almost exclusively in institutions where addicts have been confined for treatment or among those receiving psychoanalytic therapy. Psychoanalytic writings on drug addiction provide a number of plausible and sometimes convincing formulations as to the functions performed by the drug in the psychic economy. ${ }^{20}$ The inferred psychodynamics vary somewhat in the several formulations but are generally seen as part of a regressive manifestation to which orally-fiyated and narcissistic personality types are most prone. The prevalence of such narcotics-prone types in the population has not, however, been established, nor do the older psychoanalytic studies go beyond the broad theory of psychosexual development in tracing the significant developmental aspects. They do suggest that profound alterations of personality may occur in the course of addiction as a consequence of the substitution of narcotics for social and sexual realities.

Apart from the psychoanalytic studies, psychiatrists who have worked with older addicts in public hospitals for the treatment of addiction have tended to regard a high proportion of the addict population as tending toward the "psychopathic personality." Thus, of the group of early admissions to the hospital at Lexington, previously referred to, Pescor notes that eighty-eight per cent were classified under the rubrics

${ }^{10}$ DN, op. cit. stupra note 7 , at 93 .

${ }^{20}$ Among the most influential of these are the writings of Glover, Rado, and Simmel. A useful review of this literature is afforded by Crowley, Psychoanalytic Literature on Drug Addiction and Alcoholism, 26 Psychonnalytic Rev. 39 (1939). 
"psychopathic diathesis," "inebriate personality," and "psychopathic personality."21 But most of these addicts had been part of a narcotics subculture for a number of years. The majority had spent time in correctional institutions. Their interests and attitudes reflected the way of life of the criminal, the outcast, or, at very least, the self-recognized deviant. It seems highly questionable that similar personality classifications would have been made before these men became addicts. Beyond this fact, the very concept of the psychopathic personality is fraught with confusion and, to a large extent, discredited.

The more recent studies of younger addicts take one back closer to the preaddiction personality and, in this respect, would seem to permit more valid inferences. Fort, ${ }^{22}$ and Gerard and Kornetsky ${ }^{23}$ have studied young adult addicts at the Lexington hospital. They agree in regarding the bulk of the young addicts as emotionally disturbed, some of them bordering on schizophrenia, a smaller number overtly psychotic. They agree likewise that these young men manifested disturbed interpersonal relationships with peers and adults. Anxieties about difficulties in relating to others and feelings of isolation and loneliness were frequently experienced, but tended to disappear under drug influence. Problems of sexual identification and conflict over emotional impulses also characterized many of these young adults. A somewhat younger group of narcotics users, studied at Bellevue, showed similar personality tendencies, though gross pathology was less often manifest. ${ }^{24}$

The research of Gerard and Kornetsky is particularly revealing, because they also studied a control group of nonaddicts drawn from the same milieu as the addicts. Their controls were, in fact, nonusers who were friends and acquaintances of young addicts in New York City. Psychiatric interviews and projective testing suggested that the addicts studied at Lexington exhibited a significantly greater degree of disturbance along the lines noted above. The two groups were by no means clearly differentiated, however. Test responses which are generally regarded as evidences of pathology were given by a higher proportion of the addicts than of the controls, but for any given index, a substantial minority of the control subjects gave such responses and a substantial minority of the addicts gave what would be considered acceptable or normal responses. The sharpest differentiation between the two groups was afforded by the psychiatric diagnosis: none of the addict subjects were classified as normal adolescents, while forty-three per cent of the control subjects were so regarded. ${ }^{25}$ Gerard and Kornetsky classified nearly one-half of their addict group as suffering from overt or incipient schizophrenia. More than one-fifth of their controls received the same label. Two-fifths of the addict group was classified under the heading "delinquency-dominated character disorder," though none of the controls

22 Pescor, op. cit. supra note 6, at 29.

${ }^{22}$ Fort, supra note 15.

${ }^{23}$ Gerard and Kornetsky, Adolescent Opiate Addiction: A Study of Control and Addict Subjects, 29 Psychitric Q. 457 (I955).

"See Zimmering, supra note 15.

${ }^{25}$ Gerard and Kornetsky, stipra note 23, at 479 . 
was so classified. On the other hand, one-fourth of the controls were seen as suffering from "serious neurotic disturbances."

The interpretation of such psychiatric diagnoses is a difficult task. The examining psychiatrist must, perforce, know that the subject before him is either an addict or a control. By virtue of his psychiatric training, he is likely to start with the hypothesis that drug addicts are, indeed, bearers of deep psychopathology. When the addict is interviewed within a narcotics hospital, it seems likely that his responses may be somewhat different than those of a person living a free life in the community. Moreover, the examining psychiatrist and the addict are nearly always members of very different social worlds. They possess different life goals, conflicting values, antithetical loyalties. These several factors would seem to maximize the probability that a diagnosis or label of psychopathology would be placed upon the addicts studied within the narcotics hospital. The problem of different social worlds would, however, apply to a considerable degree to control subjects drawn from the same areas of the city and the same peer groups as the addicts. In the present state of knowledge of psychiatric diagnosis, it is highly questionable whether valid classifications can be made within populations whose way of life is markedly divergent from the middle-class society in which psychiatric classifications have been molded. In addition to the diagnostic problem, there is the possibility of bias due to selective factors determining who receives treatment. Only a small minority of drug users who are apprehended for narcotics possession or sale are sent to treatment settings. The majority of those receiving treatment have sought such treatment or have acquiesced to it as a result of pressures from family or others. They may differ quite significantly in personality make-up and in their integration into the subculture of drug use from the addicts who have not sought treatment. One might hypothesize that those who sought treatment felt most psychic distress and suffered most from inability to relate to others. For this reason, one cannot safely generalize findings derived from the treatment setting to the entire population of drug addicts.

Side by side with these reservations that derive from methodological considerations, there must be placed the data earlier presented on the traumatizing and distorting aspects of personality development in urban slum areas. That is, there is every reason to believe that the prevalence of personality disturbance among young persons growing up in the areas with highest rates of drug addiction is markedly greater than among young people developing in more favored neighborhoods. The latter afford both stable family settings in which the child can identify with persons who are successful by the standards of the larger society and opportunities to internalize a consistent set of moral principles while subject to a consistent set of external social controls. It is rather startling to find that studies of personality development in urban slum areas, before the advent of widespread narcotics use among young people in such areas, stressed precisely the same personality attributes and pathological developments as have been recently noted among the young addicts. 
For example, in a study of adolescents in a London slum, Spinley has observed widespread manifestation of the following characteristics: ${ }^{26}$

... a basic insecurity; a serious sexual disturbance which is associated with feminine identifications; an inability to form close affectional ties; an absence of a strong and efficient super-ego; an inability to postpone satisfaction and an absence of conflict over pleasures; a highly sensitive ego and marked narcissistic trends; a ready aggressiveness; a tendency to "leave the field" when circumstances are experienced as unpleasant; a rebellious attitude toward authority.

It would seem that the prevalence of such characteristics, coupled with the availability of narcotics and the laxness of local social controls, would constitute important predisposing influences to drug use and addiction. One may say that the level of personal vulnerability is exceedingly high, but this vulnerability does not necessarily lead to drug addiction unless a number of other conditions are met. It is quite possible that somewhat different aspects of personality or personal vulnerability tend to predispose to initial experimentation with drugs on one hand and to becoming a habitual user on the other. Wikler has observed that the intensity of drug attractiveness is enhanced for persons who have a high level of anxiety with reference to pain, hunger, and sexual urges. He suggests that degree of attractiveness of narcotics is related to personality structure, though not necessarily to neurosis and psychopathy as such. ${ }^{27}$ For persons reared in the environment that has been described, drug use would seem often to have a high functional utility.

\section{VI}

\section{The Importance of the Fanily and Patterns of Association}

It seems clear that drug addiction, whether among adolescents or among older persons, is not to be "explained" in terms of characteristics either of the environment or of the individual personality. That is to say, it is not to be explained in terms of static conditions operative at any given time. It is rather to be viewed in terms that one might use to analyze the development of a career. In any environment which affords a choice among alternatives, the individual selects out certain associations and interests in line with his past experiences and with situational influences. Certainly the most important single influence in setting early orientations toward one's choice of associates and interests is the family.

Chein's research and the psychiatric studies of younger addicts have suggested that the great bulk of addicts come from families where there were disturbed relationships between the parents and where there were vague or inconsistent standards for the boy's development. Such family types, again, seem to be widely prevalent among populations living in the most depressed areas. As we have noted, however, not all boys from such areas become delinquents or drug users. Those who resist incorporation in the delinquent subculture seem to come from families that offer more

\footnotetext{
${ }^{20}$ SPINLEY, Op. cit. supra note 18 , at 79.

${ }^{27}$ Abraham Wikler, Opiate Adpiction 55 (1953).
} 
consistent warmth and guidance to their members. This is not to say that these boys are wholly insulated from delinquency and drug use. Children from the most stable and supportive family are likely to come into contact with delinquency and drug use in the most deteriorated areas. Chein has noted, for example, that fortyfive per cent of the eighth-grade boys attending school in the highest drug use areas of New York City said they knew one or more heroin users personally, and close to forty per cent claimed to have actually seen someone taking heroin. ${ }^{28}$ At some time or other, then, as they experience life "on the street," they are likely to have a chance to participate in delinquent activities or in experimentation with drugs. Some boys, however, will have internalized a view of themselves as "good boys"; they will have internalized goals which would be threatened by delinquent or drug-using behavior. They are likely to resist incorporation into delinquent groups and to seek association with like-minded boys.

Kobrin has noted that at any given time, one can classify boys living in areas of highest delinquency rates into three groups: those who are actively and persistently delinquent, those who refrain completely from delinquent activity, and those who are occasionally delinquent. ${ }^{29}$ Over a period of time, the same individual may alternate his associations among such groups. As a definition of personal identity is established, however, and as personal ties become integrated into networks of relationship, there is likely to be a tendency toward progressive identification with one type of group and progressive alienation from the other. Such identifications and alienations will depend both upon the specific rewards or punishments that are afforded by participation in the several groups and upon the outlook for rewards from other sources.

To a considerable degree, the above formulation of career development would seem to apply not only to young drug users growing up in areas of highest delinquency and drug use in urban centers today, but also to the older addicts whose drug use was learned through association with prior addicts in the course of occupational pursuits or in the search for pleasure and freedom from restraint. This formulation does, not, of course, apply to persons whose addiction was individually arrived at as a consequence of medical treatment, nor does it apply to addictions of medical personnel who have ready access both to narcotics and to knowledge of drug effects. In such types of drug use and addiction, narcotics initially serve to relieve pain or tension and are not part of a social ritual. Concealment from all associates and friends, no matter how close, tends to be maintained as long as possible. Frequently, however, persons whose initial drug experiences were secured through medical care or through personal knowledge and access to a drug source may subsequently become incorporated into deviant groups. They may meet and establish close ties with other addicts in the course of treatment or may seek

${ }^{30}$ Chein, Studies in Narcotics Use Among Iuveniles, I Sociar WORK 50, 59 (x955).

${ }^{20}$ Kobrin, The Conflict of Values in Delinquency Areas, 16 Axs. Socrologrcal Rev. 653 (I95I). 
out such addicts in the course of achieving a social role within which addiction may be acknowledged.

\section{VII}

\section{Group Supports for Addiction and for Retapse After Cure}

The physiological processes underlying tolerance and physical dependence upon opiates and the psychiatric formulation of the problem of addiction have been described in the previous article. ${ }^{30}$ We have noted that social situations provide the opportunity for learning drug use and that shifting group and individual identifications seem to be entailed in the process of becoming a habitual user. The role of such identifications and associations in maintaining addiction and in contributing to relapse after cures must also be noted.

Lindesmith has described in some detail the importance of the first experience of withdrawal symptoms in achieving the awareness of addiction. ${ }^{31}$ There comes a time when the recently initiated drug user is either without the drug or seeks to demonstrate to himself that he can stop when he wishes. If he has become physiologically dependent, he experiences withdrawal distress. Since this distress can be quickly alleviated by the drug, there is now a tremendously important additional motivation for using the drug. It becomes a symbol of security. At the same time, there comes the admission that one is "hooked": ${ }^{32}$

As soon as the user realizes that he must begin to plan for his future supply, he is ripe for assimilation into the drug addicts' culture. It is now vital to know others of his kind from whom he must obtain his supply. He thus learns the various devices and customs by means of which his problems are solved.

The culture of the drug user has its symbols of status, its mythology, and, to a considerable extent, its own language. By these means, social solidarity among addicts is maintained. The addict is given a feeling of belonging which counters his being an outcast from the larger society. He acquires skills at the necessary transactions to secure drug supplies, usually including the skills of some type of professional criminal activity to provide a source of funds for purchasing supplies.

Again, it is useful to think of stages in a career. The user who has developed dependence upon narcotics but has not yet assured himself a relatively stable supply has been characterized as the "frantic junkie." The nature of this state and of the pressures upon the addict during it are well illustrated by the following quote from the study by the staff of the Chicago Area Project: ${ }^{33}$

An important feature of the "frantic junkie" state is that it must lead to a decisive resolution in one of two directions within a relatively short time. No person can long sustain the pressures which converge upon the "frantic junkie." Uncertain of obtaining his next shot of heroin in time to ward off illness, involved in a constant effort to steal, and

${ }^{30}$ Winick, Narcotics Addiction and Its Treatment, supra 9-33."

${ }^{31}$ ArfRed R. LINDESMTth, OpIate AdDICTION (1947).

${ }^{32} I d$. at 85 .

${ }^{33}$ Ilinois Institute for JUvenile Research, op. cit. supta note 8, at 25. 
subject to frequent arrest and detention with accompanying bouts of withdrawal illness, the young addict in this stage soon begins either to try to "kick the habit," i.e., to terminate his addiction, or to institute a more controlled use of opiates together with more planful and more successful delinquent operations. The strains and trials of this stage are related, moreover, to the problems of transition to adult status. For the young person in this situation there are only two types of adult role available: that of the professional criminal and that of the conventional adult male. Which of these courses of development come to constitute the principal adaptive trend depends entirely upon the specific elements of the person's life history.

During this stage and thereafter, if the resolution is in favor of joining the addict world, there is a tremendous preoccupation with drugs. The slightest worry or trouble causes the addict to think of drugs. The narcotic becomes the panacea for all ills. Yet, the original effectiveness of the drug diminishes, and increasing dosage must be taken not only to produce euphoria, but simply to remain normal. The ambivalence of the addict to the drug that is at the same time responsible for most of one's ills and the source of all of one's pleasures is manifested by the terms used for it. In the world of the addict, the opiates are both "God's own medicine" and "junk" or "crap."

Recognition of the effects of addiction tends to lead to efforts to give up the drig or to take a "cure." The data secured from confirmed addicts either in the community or in narcotics hospitals attest to the frequency with which cures are undertaken and the infrequency of successful ones. Moreover, for every formal cure undertaken, it appears that an addict may try many times to decrease his own drug intake. Yet, it is precisely when withdrawal symptoms make the addict most prone to give in to his yen for the drug that the desired drug effects will be most enhanced. Hence, it appears that few addicts can give up the drug without confinement in a drug-free environment.

The studies of young addicts in the community suggest that some boys who become occasional or even habitual users manage to give up drug use before they are fully "hooked." Until detailed individual histories of these boys can be analyzed, however, one can only speculate on how they escape from the tremendous pressures toward continued use, especially if they were, indeed, physically dependent upon the drug. Certainly one might hypothesize that boys who give up drugs have achieved more integrated personalities and more positive ties with the nondeviant community.

What has been called the subculture of drug addiction is not, of course, simply a matter of beliefs and practices. The addict is a member of an in-group, which may, to a degree, provide the same kind of supports that a family group would provide for other persons. Within this group, he can be himself, he can find acquiescence and enthusiasm for his views about drugs and drug effects. ${ }^{34}$ One is impressed, in reading some of the statements made by older addicts, at the rich-

\footnotetext{
${ }^{36}$ The supports provided by integration into a group which condones one's deviancy from conventional norms has been noted also in connection with homosexuality. See Leznoff and Westley, The Homosexual Community, 3 Soctal Problems 257 (I956).
} 
ness of their use of language and the sensitivity of their perceptions of their own feelings. Maurer and Vogel have noted that as addicts verbalize their reaction to drugs, they also reinforce the effect which the drugs have on them: $:^{85}$

The association of certain terms with specific experiences tends to create an associative pattern which undoubtedly plays a part in the satisfaction which the addict gets from the use of the argot. Many terms in the argot describe vividly and graphically not only the effects which drugs or abstinence from drugs produce, but also, by use of metaphor and suggestion, relate the sensations derived from drugs to other physical and emotional sensations, notably those connected with sex.

When the addict takes a cure and frees himself of the effects of narcotics, he almost never completely cuts himself off from his associations with other addicts. He cannot readily become a full participant in the conventional culture from which he has, over some period of time, been alienated. Even if he makes an effort to achieve such a transition, he is likely to have closer ties with some members of the addict community than with any persons in conventional society. For old times sake, then, he is likely occasionally to get together with such persons and, for old times sake, he is likely to take "just one" more shot. More often, it appears, the addict returns almost at once to his old associations and, thus, is subject to the full impact of drug culture.

The problem of relapse for the younger addict seems to involve similar considerations. He may be less thoroughly integrated into the addict subculture, less committed to addiction as a way of life, and more likely to have access to some groups where addiction is not a major source of preoccupation. At the same time, he is likely to be far less well prepared for competition in the occupational world and less knowledgeable of alternative opportunities outside those areas in which his life has been spent.

\section{VIII}

\section{Conceusion}

We have examined, within a social-psychological frame of reference, the phenomena of narcotics use and addiction within the contemporary United States. This has entailed consideration of factors which help to account for a high prevalence of drug use in certain types of urban areas and consideration of aspects of personality development and personal experience which seem to predispose some persons to trying narcotics or to becoming habitual users. For a majority of known drug users, the establishment of addiction is part of a career process. We have noted a number of social supports for this form of deviant behavior within settings where a large measure of deviance from the norms of the larger society is tolerated. The influences impinging upon older addicts, especially those whose addictions are learned in smaller communities, may vary somewhat from those here described,

${ }^{35}$ David W. Maurer and Victor H. Vogel, Narcotics and Narcotic Adpiction 259 (i954). 
but it is likely that the general process of becoming addicted is not markedly divergent from the outlines here sketched.

Drug use among younger persons appears to be more pervasive, in some areas of the city, than among any known older groups. The users' subculture is intertwined with that of the street society generally. But among addicts of all age groups, the meaning of addiction is to be sought in the experiences and social relationships in which drug use is learned and enmeshed. 